\title{
Designing Viable Business Models for Living Labs
}

\author{
Bernhard R. Katzy
}

\author{
"The innovation point is the pivotal moment when talented") \\ and motivated people seek the opportunity to act on their \\ ideas and dreams. \\ W. Arthur Porter \\ Professor and Executive
}

\begin{abstract}
Over 300 regions have integrated the concept of living labs into their economic development strategy since 2006, when the former Finnish Prime Minister Esko Aho launched the living lab innovation policy initiative during his term of European presidency. Despite motivating initial results, however, success cases of turning research into usable new products and services remain few and uncertainty remains on what living labs actually do and contribute. This practitioner-oriented article presents a business excellence model that shows processes of idea creation and team mobilization, new product development, user involvement, and entrepreneurship through which living labs deliver high-potential investment opportunities. Customers of living labs are identified as investors such as venture capitalists or industrial firms because living labs can generate revenue from them to create their own sustainable business model. The article concludes that living labs provide extensive support "lab" infrastructure and that it remains a formidable challenge to finance it, which calls for a more intensive debate.
\end{abstract}

\section{Introduction}

The claim of living labs is to provide new ways of involving users in (software) product development and the necessary "lab" infrastructure to do so. Living labs do not develop products, but they bring developers and users together. In short, they are intermediaries for collaborative innovation (Almirall and Warham, 2008; tinyurl.com/). Living labs are normally autonomous legal entities or separate units within larger organizations that need to finance considerable resources without which they could not execute the activities. Much of the academic writing has contributed to the conceptual understanding of the user-centricity of living labs is, what methodological innovation comes with living labs, and how they can be reconciled with rigorous research methods (e.g., Folstal, 2008; tinyurl.com/8vwtjw2). Much less has been written about their business models, which they use to create and capture value from their activities so that they can sustainably fund themselves.
Policy makers initiated - and funded - living labs with national policy objectives in mind. They aim to increase innovation performance in the European Union, a country, or region for job creation, growth, and wealth. Such policy effort is based on the idea that performance of open innovation in networks is the result of well-established and mature innovation processes with good coordination between its regional actors: small and medium entreprises and larger anchor firms, public agencies and policy makers, universities, and research centres. The ability to coordinate research and innovation into an economic development strategy is seen as a regional capacity that distinguishes successful regions (Röttmer, 2009; tinyurl.com/9vlcs8c).

It is therefore no wonder that more and more regions establish living labs with the assignment to provide process coordination for regional innovation. But policy makers mainly consider the economic effects of living labs to industry and society, and they are less con- 


\title{
Designing Viable Business Models for Living Labs
}

\author{
Bernhard R. Katzy
}

cerned with how a living lab is operated internally and what it takes to make the living lab a viable business. living lab managers do have to solve this challenge.

The aim of this practitioner-oriented article is to propose a business excellence model, which describes the processes that a living lab is made of and how they contribute to the generation of revenue for the living lab. This model is derived from an analysis by living lab directors of a number of living labs and on the basis of their experiences from multiple user-involvement projects. We take a more abstract view on the organizational design of a living labs, not the individual projects, which have been described in literature (see www.ejov.org and ice-conference.org for examples). Experience has been collected through interviews and three focus-group discussions that brought several living lab directors together. In doing so, the article presents one type of living lab in the hope of stimulating further debate on alternative designs of living labs and their improvement through benchmarking.

\section{A Business Excellence Model for Living Labs}

The idea of "business excellence models" is adopted from total quality management literature, where it is established to make explicit how an organization serves its customers and to continuously improve on its performance. For examples of business excellence models, see the EFQM Excellence Model (tinyurl.com/8vqkkhv) and the Baldrige Performance Excellence Program (tinyurl.com/3yxrzd8).

We adopt this approach here because it forces us to make it explicit who are the customers and other stakeholders of living lab services. Living labs have multiple stakeholders. They involve users, who engage in the cocreation of the product or service, and they reduce development cost for companies. Users often contribute on a voluntary basis or with very little pay but have only occasionally been reported to provide revenues for living labs. Obviously, policy makers are customers in that they ask for and finance regional innovation infrastructures. It therefore does not surprise us that living labs are strongly supported by public subsidies, but with an increasingly clear assignment to generate revenues from other, commercial activities. Living labs facilitate the early stage of product development, which is a process for which many firms search external suppliers or open innovation network partners. This is in line with the experts that we involved; they were skeptical of the notion that living labs could ever cover the entire devel- opment process until the product generates revenues. Instead, they foresee handing over a project to an industrial partner when it sufficiently mature to be an interesting investment opportunity. The business excellence model of this article therefore makes a choice in that it orients living labs towards investors as the main revenue-providing customers and structures its overall activities in three main phases, which lead to measurable intermediate results on its way:

1. Ideation phase: to scout high-potential ideas, concepts, and teams from research in university and business. The phase is completed with the commitment of a development project that brings together an executing team, the financial resources, and necessary sponsors at the match-making moment. In fact, a first valuation is made by the commitments at that moment.

2. Co-creation phase: where the living lab combines product/service development, user validation, and market positioning to prepare adoption of the solution, and entrepreneurship for the creation of a new venture. The living lab contributes coordination of the concurrently executed processes. The phase is completed with a financing deal in which innovation investors take over parts (or the whole) to further grow the venture and its product or service.

3. Venturing phase: follows standard investment processes after a project graduates from the living lab and is taken over by business angels or institutional venture capitalists. It is only in that phase that the created value becomes tangible and therefore living labs need to consider it, even though they might no longer be involved.

Business excellence models further include support processes, which form the necessary infrastructure to undertake the above-described direct processes. Living labs are frequently described as innovation infrastructures, which underlines the importance of providing collaborative IT infrastructures, quality management, and fundraising and grant management processes that are mainly targeted towards the earlier ideation and cocreation phases (Figure 1).

\section{Ideation phase}

This very early process aims at stimulating ideas for the development of a new product and in mobilizing the formation of teams, which requires active coaching by the living lab. Living labs invest in dedicated instruments for this phase such as idea fairs or business plan competitions. And they provide judgement capability 


\title{
Designing Viable Business Models for Living Labs
}

\author{
Bernhard R. Katzy
}

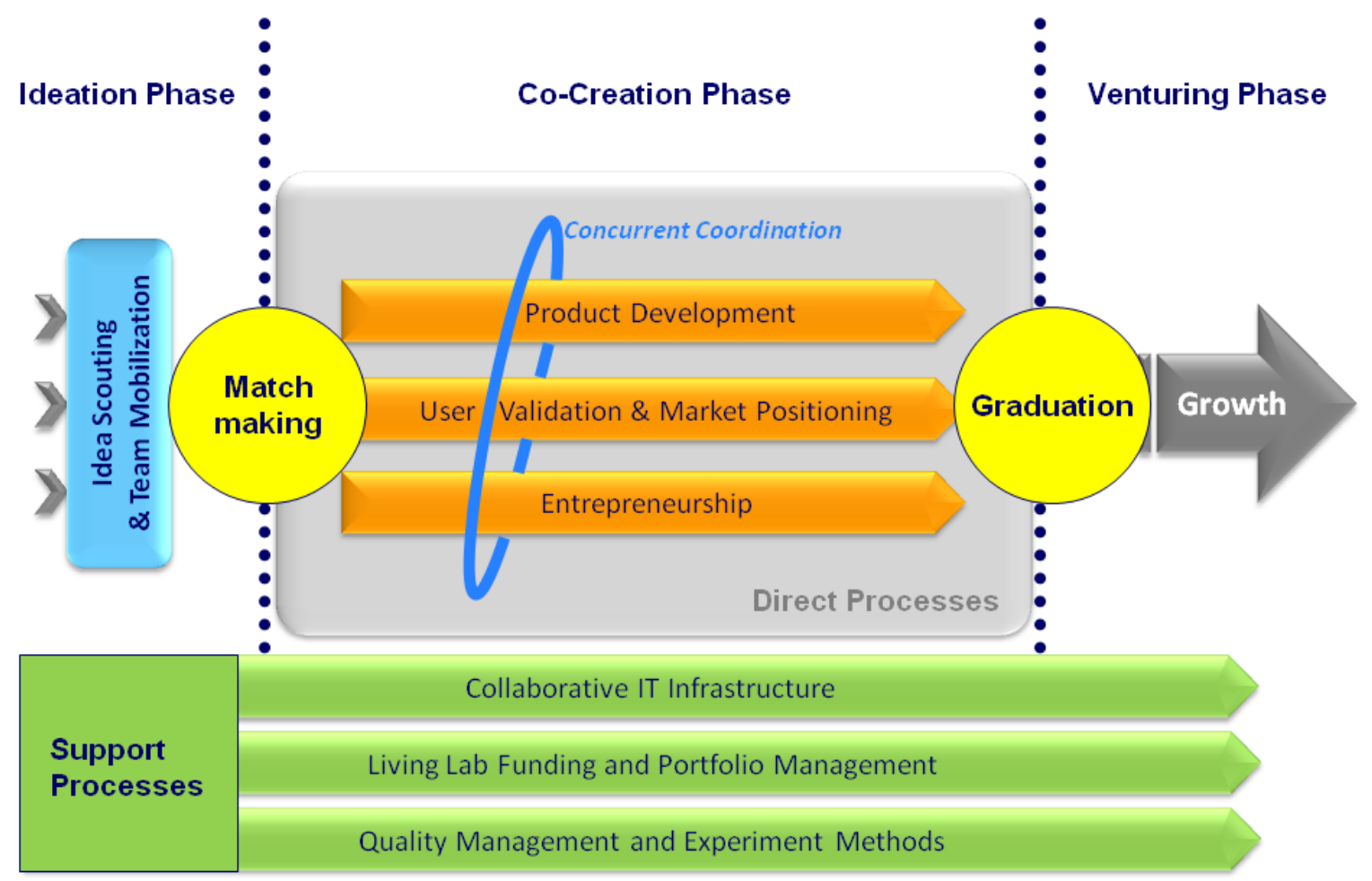

Figure 1. Living lab business excellence model

on the quality of the ideas for which expert boards, international exchange of their projects, or database research are standard instruments.

The process leads to "match making" of an investor or grant giver and a team. Experience shows that formal investment decisions create stronger team commitment and lead to a more formal structure that is beneficial to the development of the project. The living lab can enter into arrangements and be rewarded for its effort with, for example, shares of a to-be created venture.

\section{Co-creation phase}

The co-creation phase is made of three direct processes that are concurrently undertaken and therefore need tight coordination:

1. Product development support: if users shall be enabled to influence the product design, the living lab needs to provide a new product-development process that allows for rapid prototyping of ideas and concepts brought forward by users. Most development teams need access to physical tooling or software development environments that they cannot afford. FabLabs (wikipedia.org/wiki/Fab_lab) or TechShops (wikipedia.org/wiki/
TechShop) are examples of labs that specialize in manufacturing technologies to create physical products while other labs specialize in software infrastructures. Living labs further provide proficiency in practices (e.g., agile development), methods, and techniques that cut down development costs and learning time. Technical consulting competencies and specialization of resources will give each living lab a unique profile and a source of revenues in form of billable professional services.

2. User validation and marketing: user involvement in the product-development process is the dominant characteristic of living labs. It addresses the typical challenge of developing high-tech products that are highly engineered, yet often with little consideration of usability and user preferences. The process of developing a good understanding of user preferences up to their involvement in product or service co-creation is little established in industrial practice (and even less in engineering education). Development and test methodologies, access to relevant user populations, and market knowledge in a certain field are dedicated investments that shape the competence profile of a living lab. This process results not only in usability of 


\title{
Designing Viable Business Models for Living Labs
}

\author{
Bernhard R. Katzy
}

products but in more general business models for their commercialization, however this is a result that is difficult to sell by itself.

3. Entrepreneurship: user knowledge, business knowledge, and the technical knowledge of building the product are a complex bundle of knowledge and skills. A "naked" product without the development team in most cases can hardly be maintained or further developed. Therefore, many solely product-centred projects fail when the development team falls apart. A more promising alternative is to bundle knowledge, skills, brand value, and the team into an organizational structure by creating a new firm. Firm creation is the process of entrepreneurship. Structuring a new firm and establishing its organization takes time and should therefore be started from the earliest possible moment. Feedback from investor pitches further provides important additional insights for the development of a marketing case as well as for technical development. Coordinating product development with entrepreneurship brings the worlds of engineering and entrepreneurship closer together and provides the living labs with an opportunity to add value.

4. Coordinating process concurrency: Many interdependent activities need be coordinated to professionalize the innovation process and this coordination is the value creating opportunity for living labs. This starts with basic tasks such as enforcing simple discipline and making a team follow deadlines or managing projects. More complex is the management of linkages between the many parallel activities in the direct processes and the coordination of interdisciplinary teams from engineering, marketing, and entrepreneurship, which in the co-creation phase can be seen as a core competence of living labs.

\section{Venturing phase}

Projects need to graduate from the living lab after reasonable time (i.e., 6 to 18 months) to maintain innovation dynamics in the living lab. A good moment of graduation for a project is defined by achievements, of course, not by timelines: when the project has a working prototype, which ideally has generated initial revenue from pilot users and lead customers, and when the project has organizationally mutated into a business unit or an independent new venture, it is ready to move on.

The excellence of the living lab can be measured as deal-flow rate, which is the number of brokered growthfinancing deals with private investors in a short time frame. Revenues for the living lab can be generated if such deals are structured as exit options for the living lab.

\section{Designing and Implementing Living Labs}

Business excellence models are design instruments for organizations, and they help with understanding and describing structures and process. They further facilitate continuous organizational learning and improvement processes for living lab business practices.

The excellence model proposed in this article is innovative in its adaptation to the needs of coordinating innovation in living labs. Decision makers in living labs can use the business excellence model as:

1. A place to start identifying the development state of their living lab and a basis for joint action setting in/with the living lab organization.

2. A structured collection of prior living lab experiences and industrially proven practices for benchmarking.

3. A common language to support alignment of employees and external partners involved in the innovation network.

4. A means to create a shared vision and derive a performance framework to measure achievement of a living lab's goals.

\section{Creating Economic Viability with Business Models for Living Labs}

Creating an economically viable living lab means aligning internally consistent processes of a living lab organization with the needs of its external stakeholders so that revenues are generated. Public grant and subsidy programs are a dominant market of living labs in Europe but are increasingly required to serve private markets. A revenue share of $25 \%$ to $50 \%$ from private sources is typically included in grant agreements. The business excellence models described above help living labs because, at least in Europe, the bigger challenge for living labs lies in generating revenues from private markets.

Defining private markets for early-stage innovation projects is indeed not trivial. In fact, European policy makers initiated living labs in order to push market structures for early-stage innovation. It is therefore no 


\title{
Designing Viable Business Models for Living Labs
}

\author{
Bernhard R. Katzy
}

wonder that living labs face the challenges of pioneers that have to create their proper markets. An intuitive market is the provision of user validation and requirements-engineering services to other businesses. Revenues come from fees paid on a per-hour basis of professional service provision or a fixed price for a project. The advantages of this business model for living labs are low risk and relatively quick revenue generation. Some living labs generate revenues through service provision but this source of income so far remains limited because few industrial companies are willing or capable to advance investment cost both for them and the living lab. Therefore, pressure is high on living labs to share risk in the investment.

The creation of revenues through marketing of a product or service could be an alternative business model. Apart from the fact that this requires the financial capacity to bear cost until the project breaks even in their markets, the living lab would quickly focus on a few successful projects only and thus mutate from being a living lab into a supplier of these products and services. The business excellence model therefore opts for the third alternative to hand over projects to investors at them moment that they reached defined levels of maturity.

In this alternative, a living lab receives funding from individual business angels, corporate investors, or institutional venture capitalists, which are in search of investment opportunities. This model offers several advantages for both investors and living labs. For investors, living labs can lower the search costs for investable projects and teams. For living labs, projects can find investors long before they are fully developed or gain market success. Win-win constellations emerge where investors provide insights such as market knowledge on top of their financial contribution, which increases a project's chances for success. Tapping into this market, however, requires structuring projects in an appropriate way to make them investable.

What matters, therefore, for the success of the living labs is the early start of the entrepreneurship process, which creates investable projects and matches them with investors while user validation and product development are still on-going. Engineers and product developers are not normally acquainted with investors. They are unaware of potential investors and lack knowledge on how to negotiate with them, or what they need to make an investment possible. Therefore, undertaking this process is a dedicated competence to be built by the living lab.

\section{Conclusion}

Decision makers in policy and industry increasingly understand that innovation is better organized in inter-organizational cooperation, characterized by open innovation, innovation networks, triple helix processes, or clusters. Cooperation, however, is a more complex management task than purchasing through market transaction and creates challenges of its own nature. Living labs can be innovation intermediaries that provide services to make cooperation possible.

This article presents a business excellence model based on the experience of living lab directors and their reflection on their own project experience. User orientation is a necessary dimension of living labs, but it is an intangible result and not sufficient for its own economic viability. Viable business models are based on end-to-end delivery of value created for customers that are willing and able to pay for it. Not many firms can advance project investments to directly pay for living lab services. Products need be introduced into markets long before they create sales revenues. Entrepreneurship therefore emerges as a process to bridge the time gap, both for the individual development projects and for sustaining the living lab itself.

In the seed phase, and later in the growth phase, financial investors need be engaged before value becomes visible enough for customers to pay for it. Obviously user-validated products are more likely to be successful in the market, but without actual market proof, financial valuations are difficult. Creating investable projects and matching them with investors is a more feasible option. Products as such, in most cases, are not economically interesting, but require the context of their development and marketing team, intellectual properties, and brand name, a bundle that is often best valuated as a separate entity. Entrepreneurship and venturing are the two processes that bring living labs closer to such measurable valuations and a sustainable business model for themselves.

The business excellence model presented here is a practical guide for designing the organization of a living lab and the implementation of its capabilities. Maturing the competencies to execute those processes requires practice and time, often many years. To living lab founders and managers, the business excellence model provides a framework for continuous improvement of their living lab; to researchers, it provides a framework to open the "black box" of a living lab and understand the internal fabric of its organization. 


\section{Designing Viable Business Models for Living Labs}

Bernhard R. Katzy

\section{Recommended Reading}

- Special issue on living labs in the Journal of Organizational Virtualness (eJOV): (tinyurl.com/8t69drt)

\section{Acknowledgement}

This article has benefitted from discussions with many directors of living labs, especially in the EU FP 7 Gains Project, from Guido Baltes of the Knowledge Worker Living Lab in Konstanz (D), Charles Huber, Andreas Kälin and Gerhard Schwabe of the eZürich Innovation Lab, and Gideon Shimshon from the Den Haag Living Lab. Further thanks go to the reviewers of the TIM Review for their valuable comments in shaping the article.

\section{About the Author}

Bernhard R. Katzy is Professor of Technology and Innovation Management at the University BW $\mathrm{Mu}$ nich in Germany and Leiden University in The Netherlands. He is founder and director of the Center for Technology and Innovation Management (CeTIM). Bernhard was invited to be the keynote speaker at the launch event of the European Living Lab movement in December 2006, is leading the knowledgeworker living lab (one of the first wave of living labs), and is founding member of ENoLL, the association of living labs. He started his professional career with an apprenticeship as car mechanic and later earned Master of Science degrees in electrical engineering and business management. He holds a $\mathrm{PhD}$ in industrial management from University of Technology (RWTH) Aachen in Germany and a second Ph.D. (Habilitation) in general management and technology management from University of St. Gallen, Switzerland. His research interest is about entrepreneurial management of fast-growing high-tech firms and the management of strategic change in the transition to the information age.

Citation: Katzy, B. R. 2012.Designing Viable Business Models for Living Labs. Technology Innovation Management Review. September 2012: 19-24. (cc) BY 